Our results indicate that fur-farmed mink are still motivated to perform the same activities as their wild counterparts, despite being bred in captivity for 70 generations ${ }^{4}$, being raised from birth in farm conditions, and being provided with food ad libitum. The high level of stress experienced by mink denied access to the pool, rated as the most valuable resource, is evidenced by an increase in cortisol production indistinguishable from that caused by food deprivation. These results suggest that caging mink on fur farms does cause the animals frustration, mainly because they are prevented from swimming.

Georgia J. Mason*, Jonathan Cooper $\dagger$, Catherine Clarebrough ${ }^{\star}$

*Zoology Department, University of Oxford, South Parks Road, Oxford OX1 3PS, UK e-mail: georgia.mason@zoology.oxford.ac.uk

\section{Structural colour}

\section{Now you see it - now you don't}

he dazzling iridescence seen in some hummingbirds ${ }^{1}$ and tropical butterflies ${ }^{2}$ arises from natural optical phenomena, the brightest of which originate in nanoscale structures that produce ultrahigh reflectivity and narrow-band spectral purity $^{3}$. Here we investigate the coloration of male Ancyluris meliboeus Fabricius butterflies ${ }^{4}$, which have patches of unusual microstructure on their ventral wing scales. We find that this highly tilted, multilayered arrangement produces a bright iridescence of broad wavelength range and generates a strong flicker contrast from minimal wing movement.

The microstructure in the iridescent scales of A. meliboeus comprises multilayers of cuticle and air within a discrete Morpholike ${ }^{2}$ ridging that runs the length of each scale (Fig. 1a). These layers are tilted at about 30 degrees to the base of the scale, causing two distinct optical effects. In the first, abrupt termination of each cuticle layer at the upper ridge surface presents a strong periodicity of about $700 \mathrm{~nm}$, which contributes a diffractive component.

We analysed the structure's reciprocal space $^{5}$ to find out how the periodicity of the multilayers and diffracting elements scatter incident light. The diffractive component appears to combine additively with the interference from the underlying multilayer to produce a broad range of coloration, as well as a limited reverse colour change with angle compared to that associated with conventional flat multilayering.

The second, more striking effect arising from the tilted multilayering accounts for the strongly bistable nature of the wing $\uparrow$ School of Agriculture and Horticulture, De Montfort University, Caythorpe Court, Caythorpe, Lincolnshire NG32 3EP, UK

1. Animal Aid The Fur Trade Factsheet (Animal Aid, Tonbridge, 1999).

2. Dunstone, N. The Mink (Poyser Natural History, London, 1993).

3. The International Fur Trade Federation Fur Farming (http://www.iftf.com/farming/html).

4. Joergenson, G. (ed.) Mink Production (Scientifur, Hilleroed, 1985).

5. Dawkins, M. Behav. Brain Sci. 13, 1-61 (1990).

6. Rolls, E. Brain. Behav. Sci. 23, 177-200 (2000).

Hursh, S. R. J. Exp. Anal. Behav. 34, 219-238 (1980).

8. Toates, F. Stress - Conceptual and Biological Aspects (Wiley, Chichester, 1995).

9. Varian, H. Intermediate Microeconomics - A Modern Approach (Norton, New York, 1996).

10. Ng, Y.-K. Welfare Economics (Macmillan, Basingstoke, 1983).

11. Hartwick, J. M. \& Olewiler, N. D. The Economics of Natural Resource Use (Addison-Wesley, Reading, MA, 1998).

12. Reilly, S. Pharmacol. Biochem. Behav. 63, 301-311 (1999).

13. Stephens, D. W. \& Krebs, J. R. Foraging Theory (Princeton Univ. Press, NJ, 1986).

reflectivity in diffuse white light: it is either 'on', when an observer sees one of a broad range of colours, or it is 'off' and
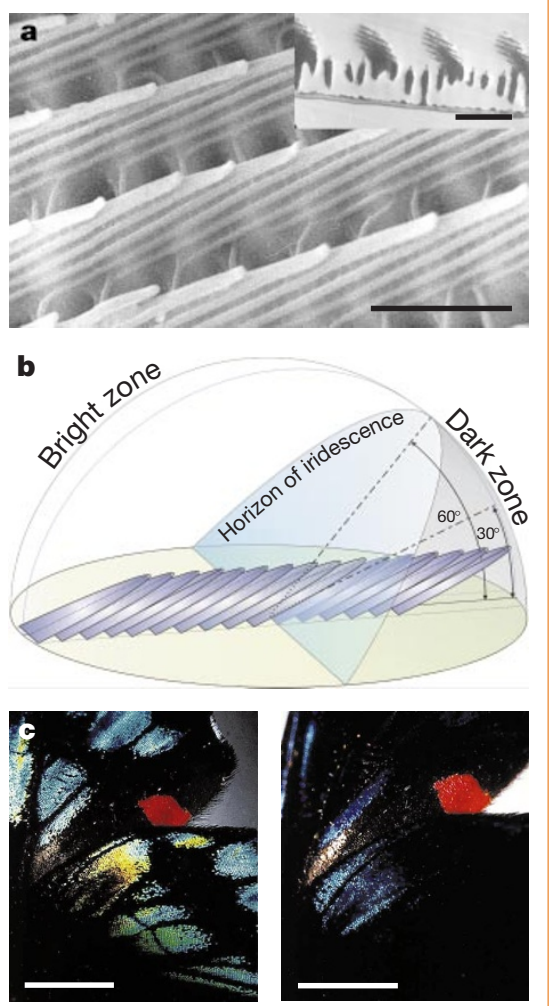

Figure 1 Tilted multilayer ridging divides the observation hemisphere above the iridescent scales of the butterfly A. meliboeus to produce strong colour flicker. a, Scanning electron microscope image of the surface of an iridescent scale. Inset, transmission electron microscope image of the cross-section through an iridescent scale at $45^{\circ}$ to the line of ridging. Scale bar, $1 \mu \mathrm{m}$ (inset, 2 $\mu \mathrm{m}) . \mathbf{b}$, Tilt-induced bright and dark zones in the observation hemisphere over an iridescent scale. c, Real-colour images showing the same portion of the butterfly's wing under diffuse illumination: left, image with the camera in the wing's bright zone; right, image after moving the camera $15^{\circ}$ round the observation hemisphere into the dark zone (the red region is coloured by pigmentation). Scale bars, $4 \mathrm{~mm}$. produces no reflected iridescence. The 30 degree layer tilt causes a 60 -degree portion of the wing's 'observation hemisphere' (Fig. 1b) not to appear iridescent ('dark zone' in Fig. 1b).

Over the remaining 120 degrees of the hemisphere, diffuse light produces iridescent reflection. Under identical illumination conditions, other structurally coloured insects and animals are seen as iridescent at angles over the entire hemisphere above their reflecting surfaces.

This structural arrangement is important in signalling by the butterfly. On or near the edge of the A. meliboeus dark zone, wing movements of no more than a few degrees generate ultra-high-contrast colour flicker in reflectivity (Fig. 1c). In species whose observation hemispheres have no dark zone, wing movements of large amplitude are necessary to achieve colour flicker.

Intermittent colour flicker is a useful conspecific trigger stimulus ${ }^{6}$, which becomes increasingly supernormal at higher and higher frequencies until the flicker-fusion frequency of the observer's visual system is reached ${ }^{7}$. However, inertial and physiological constraints usually prevent the wings from producing flicker signals at frequencies approaching those of visual flicker fusion ${ }^{6}$.

Ancyluris meliboeus avoids the need for large wing movements by means of this ingenious optical structure. By virtue of strong diffracting elements above the multilayering on its iridescent scales, this butterfly produces a broader colour range than would be accessible through interference alone - hence its alias as a "living jewel"".

P. Vukusic ${ }^{\star}$, J. R. Sambles ${ }^{\star}$, C. R. Lawrence $\dagger$, R. J. Wootton $\ddagger$

${ }^{\star}$ Thin Film Photonics, School of Physics, Exeter University, Exeter EX4 4QL, UK

e-mail:p.vukusic@ex.ac.uk

$\dagger$ Mechanical Sciences Sector, DERA, Farnborough GU14 OLX, UK

$\ddagger$ School of Biological Sciences, Exeter University, Exeter EX4 4PS, UK

1. Greenwalt, C. H., Brandt, W. \& Friel, D. D. J. Opt. Soc. Am. 50, 1005-1013 (1960).

2. Vukusic, P., Sambles, J. R., Lawrence, C. R. \& Wootton, R. J. Proc. R. Soc. Lond. B. 266, 1402-1411 (1999).

3. Land, M. F. Progr. Biophys. Molec. Biol. 24, 75-106 (1972).

4. DeVries, P. J. The Butterflies of Costa Rica and Their Natural History II: Riodinidae (Princeton Univ. Press, NJ, 1997).

5. Guinier, A. X-Ray Diffraction (Freeman, San Francisco, 1963)

6. Magnus, D. B. E. Proc. Int. Congr. Entomol. 2, 405-418 (1958).

7. Silberglied, R. E. in The Biology of Butterflies (eds Vane-Wright, R. I. \& Ackery, P. E.) 207-223 (Symp. R. Soc.11, Academic, London, 1984).

8. Smart, P. Encyclopedia of the Butterfly (Transworld, London, 1976).

erratum

A viable herd of genetically uniform cattle

P. M. Visscher et al.

Nature 409, 303 (2001)

The correct name of the last author is J. L. Williams. 